\title{
Correction to: Influence of accessibility (open and toll-based) of scholarly publications on retractions
}

\section{Tariq Ahmad Shah ${ }^{1}$. Sumeer Gul' (D) . Saimah Bashir ${ }^{3}$. Suhail Ahmad ${ }^{3}$. Assumpció Huertas $^{4}$ (D) Andrea Oliveira ${ }^{5}$ (D) - Farzana Gulzar ${ }^{6}$. Ashaq Hussain Najar ${ }^{7}$. Kanu Chakraborty ${ }^{8}$}

Published online: 19 May 2021

(c) Akadémiai Kiadó, Budapest, Hungary 2021

\section{Correction to: Scientometrics https://doi.org/10.1007/s11192-021-03990-3}

In the original publication of the article the author name Ashaq Hussain Najar and the affiliation for authors Tariq Ahmad Shah and Ashaq Hussain Najar were incorrectly displayed. These have been correction with this Correction.

Also, in the first line of the last para of the Conclusion section, the sentence, "Furthermore, the study was based on0020a..." should read as "Furthermore, the study was based on a...".

The original article has been corrected.

The original article can be found online at https://doi.org/10.1007/s11192-021-03990-3.

\section{Sumeer Gul}

sumeersuheel@gmail.com

1 Central University of Kashmir, Ganderbal, India

2 Department of Library and Information Science, University of Kashmir, Srinagar, India

3 Women Studies Center, University of Kashmir, Srinagar, India

4 Department of Communication Studies, Rovira i Virgili University, Tarragona, Spain

5 Department of Philology and Communication, University of Girona (UdG), Girona, Spain

6 Department of Management Studies, University of Kashmir, Srinagar, India

7 Department of Tourism Studies, Central University of Kashmir, Ganderbal, India

8 IIT-BHU, Varanasi, U.P, India 